\title{
Premature Death Among Primary Care Patients With a History of Self-Harm
}

\author{
Matthew J. Carr, PbD \\ Darren M. Asbcroft, PbD \\ Evangelos Kontopantelis, $\mathrm{PbD}$ \\ David Wbile, PbD \\ Yonne Awenat, MPbil \\ Jayne Cooper, $\mathrm{PbD}$ \\ Carolyn Chew-Grabam, MD \\ Nav Kapur, MD \\ Roger T. Webb, PbD
}

\begin{abstract}
PURPOSE Self-harm is a public health problem that requires a better understanding of mortality risk. We undertook a study to examine premature mortality in a nationally representative cohort of primary care patients who had harmed themselves.
\end{abstract}

METHODS During 2001-2013, a total of 385 general practices in England contributed data to the Clinical Practice Research Datalink with linkage to Office for National Statistics mortality records. We identified 30,017 persons aged 15 to 64 years with a recorded episode of self-harm. We estimated the relative risks of all-cause and cause-specific natural and unnatural mortality using a comparison cohort of 600,258 individuals matched on age, sex, and general practice.

RESULTS We found an elevated risk of dying prematurely from any cause among the self-harm cohort, especially in the first year of follow-up (adjusted hazard ratio for that year, 3.6; $95 \% \mathrm{Cl}, 3.1-4.2)$. In particular, suicide risk was especially high during the first year (adjusted hazard ratio, 54.4; 95\% Cl, 34.3-86.3); although it declined sharply, it remained much higher than that in the comparison cohort. Large elevations of risk throughout the follow-up period were also observed for accidental, alcohol-related, and drug poisoning deaths. At 10 years of follow-up, cumulative incidence values were $6.5 \%(95 \% \mathrm{Cl}, 6.0 \%-7.1 \%)$ for allcause mortality and $1.3 \%(95 \% \mathrm{Cl}, 1.2 \%-1.5 \%)$ for suicide.

CONCLUSIONS Primary care patients who have harmed themselves are at greatly increased risk of dying prematurely by natural and unnatural causes, and especially within a year of a first episode. These individuals visit clinicians at a relatively high frequency, which presents a clear opportunity for preventive action. Primary care patients with myriad comorbidities, including self-harming behavior, mental disorder, addictions, and physical illnesses, will require concerted, multipronged, multidisciplinary collaborative care approaches.

Ann Fam Med 2017;15:246-254. https://doi.org/10.1370/afm.2054.

Conflicts of interest: Dr Kapur was Chair of the Guideline Development Group for NICE clinical guideline 133 (Self-Harm: Longer-Term Management, 2011), and was Chair of the NICE Self-harm Quality Standard Topic Expert Group (2013). He is currently Chair of the Guideline Development Group for the NICE Depression in Adults guideline, and be sits on the National Suicide Prevention Advisory Group, England. The other authors report baving no conflicts of interest.

\section{CORRESPONDING AUTHOR}

Matthew J. Carr, PhD

Division of Psychology and Mental Health Faculty of Biology, Medicine and Health Room 2.309, Jean McFarlane Bldg University of Manchester Manchester Academic Health Science Centre

Oxford Road, Manchester M13 9PL, UK matthew.carr@manchester.ac.uk

\section{INTRODUCTION}

S elf-harm is a major public health problem. Deprived populations have a higher incidence of self-harm, ${ }^{1}$ and national incidence rates have risen in the wake of the economic downturn and subsequent austerity era. ${ }^{2}$ A greatly reduced life expectancy and an elevated risk of early death have been reported among people who seek care at hospitals after self-harm in Australia, ${ }^{3}$ Canada ${ }_{1}^{4}$ Denmark, ${ }^{5}$ England ${ }_{1}^{6}$ Finland ${ }_{1}^{7}$ New Zealand, ${ }^{8}$ Norway, ${ }^{9}$ Sweden, ${ }_{10}^{10}$ and Taiwan. ${ }^{11}$ Very little is known, however, about the risk of death among primary care patients who have harmed themselves. A better understanding of mortality risk in this population is needed because national clinical guidelines in England, issued by the National Institute for Health and Clinical Excellence (NICE), have emphasized the important role of general practitioners and primary health care teams in managing and monitoring risk in these patients over both shortterm $^{12}$ and long-term ${ }^{13}$ follow-up. We have previously examined clinical management after a recent self-harm episode in the same primary care patient cohort. ${ }^{14}$ We found an unexpectedly low rate of referral to mental health services, and suboptimal levels of adherence to a specific NICE rec- 
ommendation against prescribing of tricyclic antidepressant medication after self-harm, ${ }^{13,14}$ illustrating the clinical importance of examining premature mortality risk in this population.

For the study reported here, we used electronic health data linked to national mortality records to investigate the risk of dying prematurely after selfharm in a large primary care cohort in England. By examining deaths from both unnatural and natural causes, our intention was to highlight the potential clinical and public health benefits of addressing the physical health as well as the psychosocial needs of these patients. We currently know very little about long-term mortality risk in this population because researchers have traditionally tended to examine risk in the immediate post-harm period. ${ }^{4}$

\section{METHODS}

\section{Data Source}

The study was conducted using electronic health data extracted from the Clinical Practice Research Datalink (CPRD) obtained under license from the UK Medicines and Healthcare products Regulatory Agency. ${ }^{15}$ The CPRD is 1 of the world's largest population-based, longitudinal, primary care databases containing anonymized patient information provided by general practices participating in the CPRD. In the UK National Health Service (NHS), more than $98 \%$ of the population is registered with general practitioners in practices providing health care free at the point of access. In December 2013, data were available for 684 general practices and more than 13 million patients with distributions of age and sex comparable to those reported in the UK national population census. ${ }^{15,16}$ Validation studies on the CPRD have demonstrated that it contains consistent, high-quality data. ${ }^{17}$ Diagnoses are coded using the Read system that is in standard use in UK general practice. ${ }^{18} \mathrm{An}$ explanation of Read coding, and how diagnostic information is routinely recorded in the CPRD, is provided in Supplemental Appendix 1 (available at http://www. annfammed.org/content/15/3/246/suppl/DC1/).

\section{Self-Harm Definition}

We defined self-harm as "any act of self-poisoning or self-injury, irrespective of the apparent purpose," from NICE clinical guideline number $16 .{ }^{12}$ Using this broad conceptualization, we developed a list of Read codes to identify all cases of self-harm across the spectrum from milder forms of nonsuicidal behavior to near-fatal suicide attempts. The Read code list is available online (https://clinicalcodes.rss.mhs.man.ac.uk/). ${ }^{19}$ Self-harm is a commonly used term in the United Kingdom, refer- ring to all episodes irrespective of purpose $e_{i}$ cases of attempted suicide with clear intent to die represent a subset among all persons who have harmed themselves. A detailed description of the psychiatric and comorbid physical illness diagnostic categories that we examined is given in Supplemental Appendix 2 (available at http:// www.annfammed.org/content/15/3/246/suppl/DC1/).

\section{Study Cohorts}

The self-harm cohort consisted of a nationally representative sample of patients who had codes for an incident presentation of self-harm to primary care during 2001-2013 at ages 15 to 64 years. The rationale for imposing these age restrictions was that the determinants and implications of self-harm in children and older adults are distinct from those in the rest of the population, and therefore warrant separate consideration. Among older adults who harm themselves, specific mechanisms such as bereavement, loneliness, and social isolation, ${ }^{20,21}$ and physical illness, multimorbidity, and impairment ${ }^{21}$ play a greater role; children younger than 15 years who harm themselves may have less suicidal intent and a relatively low long-term risk of dying by suicide. ${ }^{22}$ Our intention was to preclude prevalentcohort bias by delineating an incident cohort, ${ }^{23,24}$ and we therefore required patients to have been registered with a contributing practice for at least 1 full year before their index episode.

Each "exposed" self-harm patient was matched with up to 20 "unexposed" patients with no record of selfharm in the CPRD at the index episode date by sex, age (year of birth), and registered practice. We applied the same eligibility criteria for entry into both the selfharm cohort and the sampling frame for the matched comparison cohort.

\section{Linked Mortality Data}

We obtained linked cause-specific mortality records and examined the underlying cause of death coded at the Office for National Statistics (ONS) using the International Classification of Diseases 10th Revision (ICD10). ${ }^{25}$ Death registration records were available for patients registered with 385 practices, approximately $60 \%$ of all CPRD practices, that is, those in England that participate in the CPRD scheme linking all patients with a valid NHS identifier. We examined both natural and unnatural causes, with the latter defined as "... external causes, e.g. injury or poisoning, which includes death due to intentional injury, such as homicide or suicide, and death caused by unintentional injury in an accidental manner." 26 Unnatural deaths were classified according to all codes listed in ICD-10 Chapter XX "External Causes of Morbidity and Mortality" (V01-Y98). ${ }^{25}$ As is accepted practice for 
UK-based epidemiologic research, our suicide definition included "open verdicts. ${ }^{.27}$ We examined natural causes because a significant proportion of people who harm themselves have a higher prevalence of lifestyle risk factors, including smoking ${ }^{28}$ and excessive drinking ${ }_{1}{ }^{29}$ that predict certain types of natural death, such as deaths from digestive diseases, respiratory diseases, and lung cancer. To examine alcohol-related deaths, which are mostly from natural causes but also include acute alcohol poisonings, we used a standard ONSendorsed coding range, ${ }^{30,31}$ and likewise for classification of drug-poisoning deaths, which include all fatal poisonings or overdoses with prescribed medication, medication purchased legally over the counter, or illicit drugs. ${ }^{32}$ The ICD-10 classifications for alcohol-related death and drug poisoning death are shown in Box 1 of Supplemental Appendix 3 (available at http://www. annfammed.org/content/15/3/246/suppl/DC1/).

\section{Area-Level Deprivation}

On the basis of patients' residential postcodes, we extracted Index of Multiple Deprivation (IMD) quintiles from the CPRD. ${ }^{33}$ The IMD measures area-level deprivation on the basis of several domains including income, employment, health, education, barriers to services (including housing), crime, and general living environment. It is derived for geographic areas designated as Lower-layer Super Output Areas (LSOAs) ${ }^{34}$ that contain 1,000 to 3,000 people and are Census derived. The IMD provides a means of ranking and assessing whether an area is more or less deprived than others.

\section{Statistical Analyses}

All analyses were performed using Stata software version 13 (StataCorp LP). For all individuals in a matched set, we defined the study entry point as the date of the index self-harm episode. We conducted Cox regression survival analysis ${ }^{35}$ stratified by matched set. We generated both unadjusted hazard ratios and those adjusted for the following potentially time dependent confounders: calendar year, frequency of contact with a general practitioner in past 12 months, mental illness diagnoses, psychotropic medication prescribed in past 12 months, clinically important alcohol misuse, and current smoking status. The methods used to generate these covariates are described in Supplemental Appendix 4 (available at http://www.annfammed. org/content/15/3/246/suppl/DC1/). Rightcensoring was applied at the end of the study period, and also to account for migra- tion from the database for reasons other than death, including geographic relocation or withdrawal of the patient's practice from the CPRD, and death from causes other than the specific cause being examined

\section{RESULTS}

\section{Descriptive Analyses}

Table 1 presents sociodemographic indices for the 30,017 persons in the self-harm cohort vs the 600,258 individuals in the matched comparison cohort on the date of the index episode. Because we matched patients on sex, age, and registered practice, the proportional breakdown in the table was identical for both groups with respect to sex, age, and practice-level deprivation. Female individuals, younger people, and those registered at practices in deprived localities were overrepresented.

Table 2 compares clinical characteristics between the self-harm and comparison cohorts at baseline, indicating that they differed markedly in terms of their patterns of clinical consultation, with the former tending to visit their practice much more frequently. Additionally, the self-harm cohort had much higher prevalences of a psychiatric history, referral to mental health services, and psychotropic medication use; alcohol misuse, smoking, and physical illness comorbidity were also considerably more prevalent in this cohort.

\section{Mortality Risk by Follow-up Year}

A key consideration when fitting a Cox model is the proportional hazards assumption, ${ }^{35}$ which requires the hazard ratio to be consistent throughout follow-up.
Table 1. Sociodemographic Characteristics at Index Self-Harm Episode

\begin{tabular}{|c|c|c|}
\hline Characteristic & $\begin{array}{c}\text { Self-Harm Cohort, } \\
\text { No. }(\%) \\
(n=30,017)\end{array}$ & $\begin{array}{c}\text { Comparison Cohort, } \\
\text { No. }(\%) \\
(n=600,258)\end{array}$ \\
\hline \multicolumn{3}{|l|}{ Sex } \\
\hline Male & $12,390(41.3)$ & $247,746(41.3)$ \\
\hline Female & $17,627(58.7)$ & $352,512(58.7)$ \\
\hline \multicolumn{3}{|l|}{ Age-group, y } \\
\hline $15-24$ & $11,876(39.6)$ & $237,470(39.6)$ \\
\hline $25-34$ & $6,028(20.1)$ & $120,541(20.1)$ \\
\hline $35-44$ & $6,132(20.4)$ & $122,665(20.4)$ \\
\hline $45-54$ & $3,995(13.3)$ & $79,869(13.3)$ \\
\hline $55-64$ & $1,986(6.6)$ & $39,696(6.6)$ \\
\hline \multicolumn{3}{|l|}{ Index of Multiple Deprivation } \\
\hline Quintile 1 (least deprived) & $3,359(11.2)$ & $67,174(11.2)$ \\
\hline Quintile 2 & $6,023(20.1)$ & $120,452(20.1)$ \\
\hline Quintile 3 & $5,571(18.6)$ & $111,412(18.6)$ \\
\hline Quintile 4 & $7,305(24.3)$ & $146,079(24.3)$ \\
\hline Quintile 5 (most deprived) & $7,759(25.9)$ & $155,141(25.9)$ \\
\hline
\end{tabular}


Table 2. Clinical Characteristics at Index Self-Harm Episode

\begin{tabular}{|c|c|c|}
\hline Characteristic & $\begin{array}{c}\text { Self-Harm Cohort, } \\
\text { No. }(\%) \\
(n=30,017)\end{array}$ & $\begin{array}{c}\text { Comparison Cohort, } \\
\text { No. }(\%) \\
(n=600,258)\end{array}$ \\
\hline \multicolumn{3}{|l|}{ General practitioner visits in past 12 mo } \\
\hline 0 visits & $2,395(8.0)$ & $152,795(25.5)$ \\
\hline $1-2$ visits & $5,217(17.4)$ & $168,467(28.1)$ \\
\hline $3-5$ visits & $6,935(23.1)$ & $143,100(23.8)$ \\
\hline$\geq 6$ visits & $15,470(51.5)$ & $135,896(22.6)$ \\
\hline \multicolumn{3}{|l|}{ Mental health history } \\
\hline Psychiatric diagnosis & $16,513(55.0)$ & $126,301(21.0)$ \\
\hline Referral to mental health services & $8,506(28.3)$ & $39,653(6.6)$ \\
\hline Psychotropic drug prescribed & $20,377(67.9)$ & $191,874(32.0)$ \\
\hline Alcohol misuse & $2,069(6.9)$ & $4,352(0.7)$ \\
\hline \multicolumn{3}{|l|}{ Physical health history } \\
\hline Asthma & $5,860(19.5)$ & $91,830(15.3)$ \\
\hline Cancer & $308(1.0)$ & $4,854(0.8)$ \\
\hline Coronary heart disease & $348(1.2)$ & $3,729(0.6)$ \\
\hline Chronic kidney disease & $114(0.4)$ & $1,400(0.2)$ \\
\hline Chronic obstructive pulmonary disease & $193(0.6)$ & $1,453(0.2)$ \\
\hline Diabetes & $849(2.8)$ & $8,896(1.5)$ \\
\hline Hypertension & $1,455(4.8)$ & $23,653(3.9)$ \\
\hline Stroke & $202(0.7)$ & $1,400(0.2)$ \\
\hline \multicolumn{3}{|l|}{ Smoking status } \\
\hline Never smoked & $9,545(36.7)$ & 286,547 (58.9) \\
\hline Current smoker & $13,507(52.0)$ & $134,538(27.7)$ \\
\hline Ex-smoker & 2,936 (11.3) & $65,306(13.4)$ \\
\hline Unknown & $4,029(-)$ & $113,867(-)$ \\
\hline
\end{tabular}

Figure 1 shows plots of hazard ratios and their 95\% CIs stratified by individual follow-up year. For all-cause mortality (Figure $1 \mathrm{~A}$ ), suicide (Figure $1 \mathrm{~B}$ ), natural death (Figure 1C), and unnatural death (Figure 1D), by far the greatest elevations in risk occurred during the first follow-up year. For natural death, the magnitude of the observed hazard ratio declined gradually in annual increments from the first to the fourth follow-up year, whereas for suicide and for all unnatural deaths combined, risk was markedly higher for the first year than it was during the ensuing 9 years of follow-up. Because mortality risk was found to be elevated to a greater degree during the first follow-up year than for subsequent years in all 4 of these plots, we accounted for nonproportionality in risk ${ }^{35}$ over time for all the hazard ratios presented in Tables 3 and 4. For these tabulations, we therefore estimated 2-stage hazard ratios separately, that is, for the first year of follow-up and for follow-up thereafter.

\section{Relative Risk of Early Mortality}

Two-stage hazard ratio estimates for all-cause mortality, mortality from all natural causes, and mortality from all unnatural causes are presented in Table 3 . We found 2 consistent patterns across these 3 broad mortality categories: (1) much greater risk during the first year vs subsequent follow-up years and (2) attenuated but still significant elevations in risk after covariate adjustment. Although a greater number of natural deaths were observed, the hazard ratios for unnatural death were considerably larger. Smaller effect sizes were observed for natural death, although even with this outcome, an independent statistically significant elevation in risk persisted after adjustment.

In Table 4 we present hazard ratios for the following specific causes of death: suicide, accidents, alcohol-related, drug poisoning, respiratory disease, and lung cancer. Self-harm was a strong and significant predictor for each of these outcomes, and the greatest risk elevations were for suicide. The increase in risk was more pronounced in the first year vs subsequent follow-up years, especially so for suicide. We did not observe any notable sex differences in the observed hazard ratios: likelihood ratio tests on sex interactions were not statistically significant for all causes of death $(P=.09)$, all natural causes $(P=.55)$, all unnatural causes $(P=.18)$, and suicide $(P=.14)$.

\section{Cumulative Incidence of Premature Death}

Absolute risks are shown in Table 5. The numbers of deaths are summarized at varying lengths of follow-up after the index self-harm episode for the self-harm and comparison cohorts along with cumulative incidence values (presented as percentages). At 10 years of follow-up, the cumulative incidence values in this predominantly younger cohort of people who had harmed themselves were 6.5\% (95\% CI, 6.0\%-7.1\%) for all-cause mortality and $1.3 \%$ (95\% CI, 1.2\%-1.5\%) for suicide.

\section{DISCUSSION}

\section{Summary of Findings}

Compared with a matched cohort of unaffected individuals, the self-harm cohort had a markedly increased risk of unnatural death during the first follow-up year. Beyond the first year, risk remained elevated vs the comparison cohort, but to a considerably lesser degree. 


\section{Figure 1. Hazard ratios for death due to various causes, stratified by individual follow-up year.}
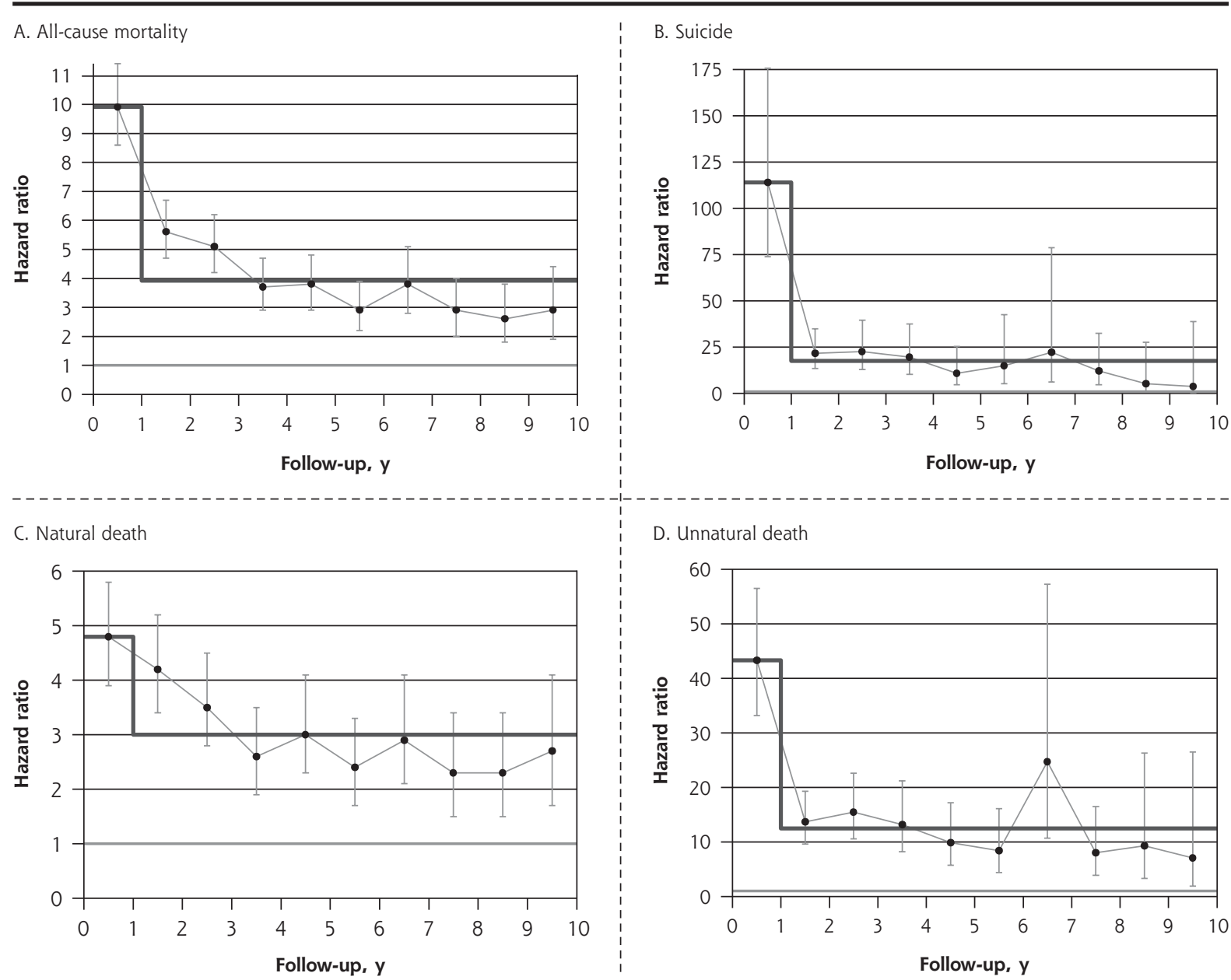

D. Unnatural death

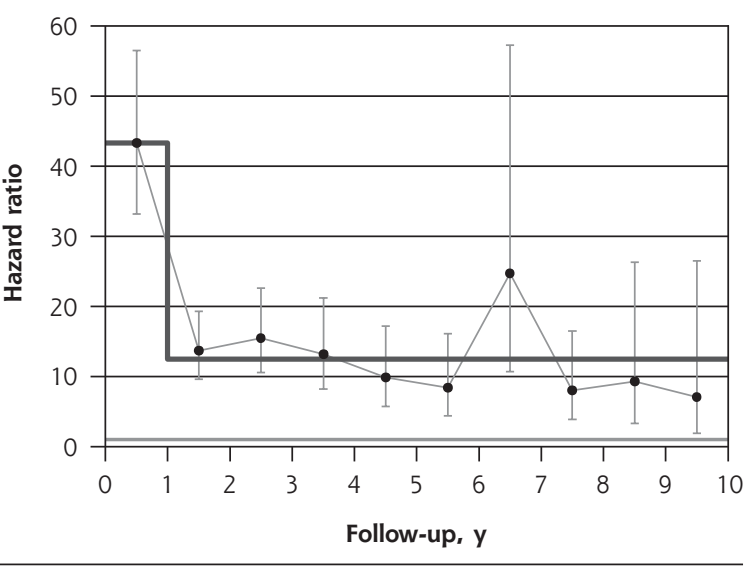

Notes: Hazard ratios for self-harm cohort vs comparison cohort. Note that $y$-axis scales differ. Dark gray line indicates modeled 2-stage trend. Light gray line indicates unity (1).

The largest elevation in risk within a year of the index self-harm episode and over longer term follow-up was for suicide. Risk of dying prematurely from a natural cause was elevated for both follow-up periods, albeit to a much lesser degree than for dying by unnatural causes. Risks were increased across a broad array of cause-specific premature mortality outcomes, including suicide, accident, and alcohol-related, drug poisoning, respiratory disease, and lung cancer death.

\section{Comparison With Existing Evidence}

For the first time, we report short- and long-term mortality risk in UK primary care patients whose episodes of self-harming behavior may or may not be known to hospital services. Our findings also confirm those from earlier investigations that have reported an elevated risk of unnatural and natural mortality after self-harm. ${ }^{3-11,36-40}$ It is important, however, to highlight that almost all previously published studies ascertained index self-harm episodes via secondary care data sources, mostly through emergency department contacts, although a small number of study cohorts were drawn from specialized poisoning treatment centers. ${ }^{36}$ Virtually all previous studies have reported relative risks for cause-specific mortality without stratifying these estimates by length of follow-up. For some smaller studies, these estimates may have been aggregated across the whole observation period to maximize statistical power. Our proportional hazards assumption testing ${ }^{35}$ revealed that such data pooling may yield invalid estimates averaged across the whole duration of follow-up if the degree of risk elevation is substantially greater during the first year. Few investigations have reported relative risk restricted to the first follow-up year ${ }_{i} 2$ Taiwanese studies (1 conducted in Nantou County ${ }^{41}$ and the other in Taipei City ${ }^{11}$ found age- and sex-adjusted 
elevations of risk by 100 -fold or more. The Multicentre Study of Self-harm in England, conducted in the cities of Derby, Manchester, and Oxford, reported on the shared characteristics and similarity of risk factors for suicide and accidental death after self-harm. ${ }^{41}$ It is therefore noteworthy that, in our study, risk of accidental death was also greatly elevated in the self-harm cohort.

\section{Strengths and Limitations}

Our study had several major strengths. For the first time, we examined risks of all-cause and cause-specific premature death in a nationally representative primary care cohort, with complete case ascertainment via linkage to national mortality records. We used an optimal study design by comparing risks directly at the individual patient level between an incident self-harm cohort and an unaffected comparison cohort sampled from the same population. This is a more robust approach than comparing risk indirectly via age- and sex-standardized mortality ratios calculated using nationally aggregated data, as was reported in previous studies. ${ }^{5}$ By delineating an incident cohort design, we precluded prevalentcohort bias, ${ }^{23,24}$ which underestimates the strength of exposure-outcome associations, and which could have influenced previous investigations of this topic. ${ }^{3-11}$ Finally, our design was further enhanced by having up to 20 matched comparison individuals for every person in the self-harm cohort to enable examination of mortality outcomes that are particularly rare in the general population, such as suicide.

The study also had some limitations. First, we lacked the ability to examine confounding or effect

Table 3. Hazard Ratios for Deaths Due to All Causes, All Natural Causes, and All Unnatural Causes

\begin{tabular}{|c|c|c|c|c|c|}
\hline \multirow[b]{2}{*}{ Cause of Death ${ }^{b}$} & \multirow[b]{2}{*}{$\begin{array}{l}\text { Follow-up } \\
\text { Period }\end{array}$} & \multicolumn{2}{|c|}{ Self-Harm Cohort } & \multicolumn{2}{|c|}{ Hazard Ratio ${ }^{a}(95 \% \mathrm{Cl})$} \\
\hline & & $\begin{array}{l}\text { Deaths, } \\
\text { No. }\end{array}$ & $\begin{array}{l}\% \text { per } 1,000 \\
\text { Person-Years }\end{array}$ & Unadjusted & Adjusted ${ }^{c}$ \\
\hline \multirow[t]{2}{*}{ All causes } & $\leq 1 \mathrm{y}$ & 301 & 11.1 & $9.92(8.63-11.40)$ & $3.59(3.08-4.19)$ \\
\hline & $>1 y$ & 673 & 6.3 & $3.92(3.61-4.27)$ & $1.70(1.54-1.88)$ \\
\hline \multirow[t]{2}{*}{ All natural causes } & $\leq 1 \mathrm{y}$ & 126 & 4.6 & $4.79(3.94-5.82)$ & $1.51(1.11-1.87)$ \\
\hline & $>1 y$ & 459 & 4.3 & $2.98(2.69-3.29)$ & $1.25(1.11-1.40)$ \\
\hline \multirow[t]{2}{*}{ All unnatural causes } & $\leq 1 \mathrm{y}$ & 175 & 6.4 & $43.31(33.20-56.49)$ & $21.11(15.83-28.15)$ \\
\hline & $>1 y$ & 214 & 2.0 & $12.53(10.48-14.99)$ & $5.65(4.60-6.94)$ \\
\hline
\end{tabular}

a Two-stage hazard ratios for the self-harm cohort vs the comparison cohort.

${ }^{b}$ Deaths were delineated using International Classification of Diseases 10th Revision (ICD-10) codes: unnatural death, codes V01-Y98; natural death, any code other than V01-Y98. ' Adjusted for visit frequency in previous 12 months, history of psychiatric diagnoses, history of mental health referral, history of psychotropic medication prescribing, history of alcohol misuse, and smoking status.

Table 4. Hazard Ratios for Deaths Due to Specific Causes

\begin{tabular}{|c|c|c|c|c|c|}
\hline \multirow[b]{2}{*}{ Cause of Death } & \multirow[b]{2}{*}{$\begin{array}{l}\text { Follow-up } \\
\text { Period }\end{array}$} & \multicolumn{2}{|c|}{ Self-Harm Cohort } & \multicolumn{2}{|c|}{ Hazard Ratio ${ }^{a}(95 \% \mathrm{Cl})$} \\
\hline & & $\begin{array}{l}\text { Deaths, } \\
\text { No. }\end{array}$ & $\begin{array}{l}\% \text { per } 1,000 \\
\text { Person-Years }\end{array}$ & Unadjusted & Adjusted $^{\mathrm{c}}$ \\
\hline \multirow[t]{2}{*}{ Suicide } & $\leq 1 \mathrm{y}$ & 140 & 5.1 & $113.90(73.87-175.63)$ & $54.43(34.32-86.32)$ \\
\hline & $>1 \mathrm{y}$ & 122 & 1.1 & $17.45(13.50-22.54)$ & $7.62(5.67-10.25)$ \\
\hline \multirow[t]{2}{*}{ Accident } & $\leq 1 \mathrm{y}$ & 35 & 1.3 & $12.94(8.45-19.84)$ & $5.60(3.45-9.08)$ \\
\hline & $>1 \mathrm{y}$ & 90 & 0.8 & $9.32(7.19-12.08)$ & $4.16(3.05-5.65)$ \\
\hline \multirow[t]{2}{*}{ Alcohol related } & $\leq 1 \mathrm{y}$ & 26 & 1.0 & $14.52(8.74-24.11)$ & $2.62(1.14-6.02)$ \\
\hline & $>1 \mathrm{y}$ & 106 & 1.0 & $11.16(8.72-14.29)$ & $2.37(1.50-3.76)$ \\
\hline \multirow[t]{2}{*}{ Drug poisoning } & $\leq 1 \mathrm{y}$ & 49 & 1.8 & $48.17(28.63-81.03)$ & $17.62(9.83-31.58)$ \\
\hline & $>1 \mathrm{y}$ & 91 & 0.8 & $28.46(20.25-39.98)$ & $9.22(6.14-13.83)$ \\
\hline \multirow[t]{2}{*}{ Respiratory disease } & $\leq 1 \mathrm{y}$ & 11 & 0.4 & $6.39(3.24-12.61)$ & $2.64(1.22-5.70)$ \\
\hline & $>1 y$ & 53 & 0.5 & $4.94(3.63-6.72)$ & $2.21(1.55-3.15)$ \\
\hline \multirow[t]{2}{*}{ Lung cancer } & $\leq 1 \mathrm{y}$ & 9 & 0.3 & $4.55(2.20-9.39)$ & $2.31(1.00-5.30)$ \\
\hline & $>1 \mathrm{y}$ & 29 & 0.3 & $1.92(1.31-2.82)$ & $0.88(0.56-1.37)$ \\
\hline \multicolumn{6}{|c|}{$\begin{array}{l}\text { b Causes of death delineated using the following International Classification of Diseases 10th Revision (ICD-10) codes: suicide: X60-X84, Y10-Y34 (excluding Y33.9), Y87.0, } \\
\text { Y87.2; accident: V01-X59, Y85-Y86, Y87.1; alcohol related: F10, G31.1, 142.6, K29.2, K70, K73, K74 (excluding K74.3-K74.5), K86.0, X45, X65, Y15; drug poisoning: } \\
\text { F11-F16, F18-F19, X40-X44, X60-X64, X85, Y10-Y14; respiratory disease: J00-J99; lung cancer: C33-C34. }\end{array}$} \\
\hline \multicolumn{6}{|c|}{$\begin{array}{l}\text { 'Adjusted for visit frequency in previous } 12 \text { months, history of psychiatric diagnoses, history of mental health referral, history of psychotropic medication prescribing, } \\
\text { history of alcohol misuse, and smoking status. }\end{array}$} \\
\hline
\end{tabular}


Table 5. Cumulative Incidence of Deaths Due to All Causes and Specific Causes

\begin{tabular}{|c|c|c|c|c|}
\hline \multirow[b]{2}{*}{ Cause of Death ${ }^{a}$} & \multicolumn{2}{|c|}{$\begin{array}{l}\text { Self-Harm Cohort } \\
(n=30,017)\end{array}$} & \multicolumn{2}{|c|}{$\begin{array}{l}\text { Comparison Cohort } \\
(n=600,258)\end{array}$} \\
\hline & $\begin{array}{l}\text { Deaths, } \\
\text { No. }\end{array}$ & $\begin{array}{l}\text { Cumulative } \\
\text { Incidence, \% } \\
(95 \% \mathrm{Cl})\end{array}$ & $\begin{array}{l}\text { Deaths, } \\
\text { No. }\end{array}$ & $\begin{array}{l}\text { Cumulative } \\
\text { Incidence, \% } \\
(95 \% \mathrm{Cl})\end{array}$ \\
\hline \multicolumn{5}{|l|}{ All causes } \\
\hline At $1 \mathrm{y}$ & 301 & $1.07(0.96-1.20)$ & 634 & $0.11(0.10-0.12)$ \\
\hline At $5 \mathrm{y}$ & 739 & $3.47(3.22-3.73)$ & 2,777 & $0.68(0.66-0.71)$ \\
\hline At $10 y$ & 946 & $6.53(6.04-7.06)$ & 4,455 & $1.79(1.73-1.85)$ \\
\hline \multicolumn{5}{|l|}{ All natural causes } \\
\hline At $1 \mathrm{y}$ & 126 & $0.46(0.38-0.54)$ & 551 & $0.10(0.09-0.11)$ \\
\hline At 5 y & 406 & $2.01(1.82-2.22)$ & 2,435 & $0.60(0.58-0.63)$ \\
\hline At $10 \mathrm{y}$ & 563 & $4.43(4.00-4.90)$ & 3,989 & $1.63(1.57-1.69)$ \\
\hline \multicolumn{5}{|l|}{ All unnatural causes } \\
\hline At $1 \mathrm{y}$ & 175 & $0.62(0.53-0.72)$ & 83 & $0.01(0.01-0.02)$ \\
\hline At $5 \mathrm{y}$ & 333 & $1.49(1.33-1.66)$ & 342 & $0.08(0.07-0.09)$ \\
\hline At $10 y$ & 383 & $2.21(1.95-2.49)$ & 466 & $0.16(0.15-0.18)$ \\
\hline \multicolumn{5}{|l|}{ Suicide } \\
\hline At $1 \mathrm{y}$ & 140 & $0.50(0.42-0.58)$ & 27 & $0.00(0.00-0.01)$ \\
\hline At $5 \mathrm{y}$ & 234 & $1.00(0.88-1.14)$ & 131 & $0.03(0.03-0.04)$ \\
\hline At $10 y$ & 258 & $1.33(1.15-1.53)$ & 182 & 0.07 (0.06-0.08) \\
\hline \multicolumn{5}{|l|}{ Accidental } \\
\hline At $1 \mathrm{y}$ & 35 & $0.12(0.09-0.17)$ & 54 & $0.01(0.01-0.01)$ \\
\hline At $5 \mathrm{y}$ & 97 & $0.48(0.39-0.59)$ & 201 & $0.05(0.04-0.05)$ \\
\hline At $10 \mathrm{y}$ & 123 & 0.88 (0.70-1.09) & 273 & $0.09(0.08-0.11)$ \\
\hline \multicolumn{5}{|l|}{ Alcohol related } \\
\hline At $1 \mathrm{y}$ & 26 & $0.09(0.06-0.14)$ & 40 & $0.01(0.01-0.01)$ \\
\hline At $5 \mathrm{y}$ & 94 & $0.48(0.39-0.59)$ & 165 & $0.04(0.03-0.05)$ \\
\hline At $10 y$ & 132 & $1.03(0.84-1.27)$ & 260 & $0.10(0.09-0.12)$ \\
\hline \multicolumn{5}{|l|}{ Drug poisoning } \\
\hline At $1 \mathrm{y}$ & 49 & $0.17(0.13-0.23)$ & 20 & $0.00(0.00-0.01)$ \\
\hline At $5 y$ & 116 & $0.54(0.45-0.65)$ & 73 & $0.02(0.01-0.02)$ \\
\hline At $10 y$ & 138 & $0.86(0.70-1.06)$ & 90 & $0.03(0.02-0.03)$ \\
\hline
\end{tabular}

field, do not capture a population of higher-risk individuals compared with all registered primary care patients who have harmed themselves. From this information, we can infer a strong and clinically important message for primary health care teams: these patients have a greatly elevated risk of suicide and other causes of premature death, especially within a year of their known self-harm episode. National guidelines could provide more specific recommendations and training on how primary health care teams can intervene, manage, and monitor risk in these patients more effectively. ${ }^{42}$ Some of the risk factors identified, particularly alcohol misuse and smoking, are potentially modifiable. Furthermore, people who have harmed themselves visit clinicians much more frequently than their age- and sex-matched peers, which presents a clear opportunity for preventive action. Primary care patients with myriad comorbidities, including self-harming behavior, mental disorders, addictions, and physical illnesses, will require a concerted, multipronged, multidisciplinary collaborative approach to care to enhance management of their complex health needs. ${ }^{43}$

To read or post commentaries in response to this article, see it online at http:/lwww. AnnFamMed.org/content/15/3/246. modification by ethnicity and individual-level socioeconomic status (beyond a score allocated at the patient postcode level). Second, the mortality record linkage scheme implemented for most CPRD practices in England did not yet exist for CPRD practices in Scotland, Wales, or Northern Ireland when the study was conducted. Our findings may therefore not be generalizable to the entire UK population.

\section{Interpretation and Implications}

These findings should dispel any notion that a primary care patient cohort with a recorded history of self-harm would have an appreciably lower risk of dying prematurely by suicide and other unnatural and natural causes of death than individuals identified by hospital emergency department contacts. Our results suggest that secondary care study cohorts, which are the predominant setting for research conducted in the
Key words: self-harm; general practice; mortality; suicide; primary care; practice-based research

Submitted September 16, 2016; submitted, revised, December 16, 2016; accepted December 30, 2016.

Author affiliations: Division of Psychology and Mental Health, Faculty of Biology, Medicine and Health, University of Manchester, Manchester Academic Health Science Centre, Manchester M13 9PL, UK (Carr, While, Awenat, Cooper, Kapur, Webb); Division of Pharmacy and Optometry, Faculty of Biology, Medicine and Health, University of Manchester, Manchester Academic Health Science Centre, Manchester M13 9PL, UK (Ashcroft); NIHR Greater Manchester Primary Care Patient Safety Translational Research Centre, Manchester M13 9PL, UK (Ash(roft); Division of Informatics, Imaging and Data Sciences, Faculty of Biology, Medicine and Health, University of Manchester, Manchester Academic Health Science Centre, Manchester M13 9PL, UK (Kontopantelis); Research Institute of Primary Care and Health Sciences, Keele University, Staffordshire ST5 5BG, UK (Chew-Graham); West Midlands NIHR Collaborative Leadership in Applied Health Research and Care (CLAHRC), Birmingham, UK (Chew-Graham). 
Funding support: This work was supported by the Department of Health Policy Research Programme Suicide Prevention call (Self-harm in Primary Care Patients: A Nationally Representative Cohort Study Examining Patterns of Attendance, Treatment and Referral, and Risk of Selfharm Repetition, Suicide and Other Causes of Premature Death; RDD 023/0166). N.K. is funded in part by the Manchester Mental Health and Social Care Trust, and C.C.-G. is funded in part by the National Institute for Health Research (NIHR) Collaborations for Leadership in Applied Health Research and Care West Midlands. E.K.'s time and facilities were also supported by MRC Health eResearch Centre (HeRC) grant no. MR/K006665/1.

Disclaimer: The views expressed in this publication are those of the authors and not necessarily those of the Department of Health or the UK Medicines and Healthcare products Regulatory Agency (MHRA).

Acknowledgments: This study is based on data from the Clinical Practice Research Datalink (CPRD) obtained under license from the MHRA. The study was approved by the Independent Scientific Advisory Committee (ISAC) for CPRD-based research (Ref. 13_122ARA2). We would also like to acknowledge the contribution of our Patient and Public Involvement (PPI) partners, whom we liaised with from inception to completion of the study.

Supplementary materials: Available at http://www. AnnFamMed. org/content/15/3/246/suppl/DC1/.

\section{References}

1. Carr MJ, Ashcroft DM, Kontopantelis E, et al. The epidemiology of self-harm in a UK-wide primary care patient cohort, 2001-2013. BMC Psychiatry. 2016;16(1):53.

2. Corcoran P, Griffin E, Arensman E, Fitzgerald AP, Perry IJ. Impact of the economic recession and subsequent austerity on suicide and self-harm in Ireland: An interrupted time series analysis. Int J Epidemiol. 2015;44(3):969-977.

3. Reith DM, Whyte I, Carter G, McPherson M, Carter N. Risk factors for suicide and other deaths following hospital treated selfpoisoning in Australia. Aust N Z J Psychiatry. 2004;38(7):520-525.

4. Finkelstein Y, Macdonald EM, Hollands S, et al; Canadian Drug Safety and Effectiveness Research Network (CDSERN). Risk of suicide following deliberate self-poisoning. JAMA Psychiatry. 2015;72 (6): $570-575$.

5. Christiansen E, Jensen BF. Risk of repetition of suicide attempt, suicide or all deaths after an episode of attempted suicide: a registerbased survival analysis. Aust N Z J Psychiatry. 2007;41(3):257-265.

6. Bergen $\mathrm{H}$, Hawton $\mathrm{K}$, Waters $\mathrm{K}$, et al. Premature death after selfharm: a multicentre cohort study. Lancet. 2012;380(9853):1568-1574.

7. Suominen K, Isometsä E, Haukka J, Lönnqvist J. Substance use and male gender as risk factors for deaths and suicide-a 5-year follow-up study after deliberate self-harm. Soc Psychiatry Psychiatr Epidemiol. 2004;39(9):720-724.

8. Gibb SJ, Beautrais AL, Fergusson DM. Mortality and further suicidal behaviour after an index suicide attempt: a 10-year study. Aust N Z J Psychiatry. 2005;39(1-2):95-100.

9. Bjornaas MA, Jacobsen D, Haldorsen T, Ekeberg O. Mortality and causes of death after hospital-treated self-poisoning in Oslo: a 20-year follow-up. Clin Toxicol (Phila). 2009;47(2):116-123.

10. Tidemalm D, Beckman K, Dahlin M, et al. Age-specific suicide mortality following non-fatal self-harm: national cohort study in Sweden. Psychol Med. 2015;45(8):1699-1707.

11. Kuo CJ, Gunnell D, Chen CC, Yip PS, Chen YY. Suicide and nonsuicide mortality after self-harm in Taipei City, Taiwan. Br J Psychiatry. 2012;200(5):405-411.
12. National Institute for Clinical Excellence (NICE). Self-harm: the short-term physical and psychological management and secondary prevention of self-harm in primary and secondary care. NICE guideline CG16;2004. https://www.nice.org.uk/guidance/cg16. Published Jul 2004.

13. National Institute for Health and Clinical Excellence (NICE). Selfharm: longer-term management. NICE guideline CG133;2011. https://www.nice.org.uk/guidance/cg133. Published Nov 2011. Accessed Dec 14, 2016.

14. Carr MJ, Ashcroft DM, Kontopantelis E, et al. Clinical management following self-harm in a UK-wide primary care cohort. J Affect Disord. 2016;197:182-188.

15. Herrett E, Gallagher AM, Bhaskaran K, et al. Data resource profile: Clinical Practice Research Datalink (CPRD). Int J Epidemiol. 2015;44(3):827-836.

16. García Rodríguez LA, Pérez Gutthann S. Use of the UK General Practice Research Database for pharmacoepidemiology. Br J Clin Pharmacol. 1998;45(5):419-425.

17. Khan NF, Harrison SE, Rose PW. Validity of diagnostic coding within the General Practice Research Database: a systematic review. BrJ Gen Pract. 2010;60(572):e128-e136.

18. Chisholm J. The Read clinical classification. BMJ. 1990;300(6732): 1092.

19. Springate DA, Kontopantelis E, Ashcroft DM, et al. ClinicalCodes: an online clinical codes repository to improve the validity and reproducibility of research using electronic medical records. PLoS ONE. 2014;9(6):e99825.

20. De Leo D, Padoani W, Scocco P, et al. Attempted and completed suicide in older subjects: results from the WHO/EURO Multicentre Study of Suicidal Behaviour. Int J Geriatr Psychiatry. 2001;16(3):300-310.

21. Lebret S, Perret-Vaille E, Mulliez A, Gerbaud L, Jalenques I. Elderly suicide attempters: characteristics and outcome. Int J Geriatr Psychiatry. 2006;21(11):1052-1059.

22. Hawton K, Harriss L. Deliberate self-harm by under-15-year-olds: characteristics, trends and outcome. J Child Psychol Psychiatry. 2008;49(4):441-448.

23. Brookmeyer R, Gail MH. Biases in prevalent cohorts. Biometrics. 1987;43(4):739-749.

24. Heaton B, Applebaum KM, Rothman KJ, et al. The influence of prevalent cohort bias in the association between periodontal disease progression and incident coronary heart disease. Ann Epidemiol. 2014;24(10):741-746.

25. World Health Organization (WHO). Manual of the International Classification of Diseases, 10th Revision (ICD-10). Geneva, Switzerland: World Health Organization;1992.

26. The Free Dictionary by Farlex. Medical dictionary. http://medicaldictionary.thefreedictionary.com/. Accessed Dec 14, 2016.

27. Linsley KR, Schapira K, Kelly TP. Open verdict v. suicide - importance to research. Br J Psychiatry. 2001;178:465-468.

28. McMahon EM, Corcoran P, Keeley H, Perry IJ, Arensman E. Adolescents exposed to suicidal behavior of others: prevalence of selfharm and associated psychological, lifestyle, and life event factors. Suicide Life Threat Behav. 2013;43(6):634-45.

29. Ness J, Hawton $\mathrm{K}$, Bergen $\mathrm{H}$, et al. Alcohol use and misuse, selfharm and subsequent mortality: an epidemiological and longitudinal study from the multicentre study of self-harm in England. Emerg Med J. 2015;32(10):793-799.

30. Breakwell C, Baker A, Griffiths C, Jackson G, Fegan G, Marshall D. Trends and geographical variations in alcohol-related deaths in the United Kingdom, 1991-2004. Health Stat Q. 2007;33(33):6-24.

31. Bergen $\mathrm{H}$, Hawton $\mathrm{K}$, Webb R, et al. Alcohol-related mortality following self-harm: a multicentre cohort study. JRSM Open. 2014;5(8):2054270414533326. 
32. Office for National Statistics (ONS). Deaths related to drug poisoning in England and Wales: Quality and Methodology Information. https://www.ons.gov.uk/peoplepopulationandcommunity/ birthsdeathsandmarriages/deaths/qmis/deathsrelatedtodrugpoisoninginenglandandwalesqmi. Updated Sep 2014. Accessed Dec 14, 2016.

33. Department for Communities and Local Government. The English indices of deprivation 2010: technical report. https://www. gov.uk/government/uploads/system/uploads/attachment_data/ file/6320/1870718.pdf. Published Mar 2011. Accessed Oct 26, 2015.

34. Office for National Statistics. Super Output Area (SOA). http://www. ons.gov.uk/ons/guide-method/geography/beginner-s-guide/census/ super-output-areas--soas-/index.html. Accessed Oct 26, 2015.

35. Cox DR. Regression models and life tables (with discussion). J R Stat Soc B. 1972;34(2):187-220.

36. Nordentoft M, Breum L, Munck LK, Nordestgaard AG, Hunding A, Laursen Bjaeldager PA. High mortality by natural and unnatural causes: a 10 year follow up study of patients admitted to a poisoning treatment centre after suicide attempts. BMJ. 1993;306(6893): 1637-1641.

37. Carter G, Reith DM, Whyte IM, McPherson M. Non-suicidal deaths following hospital-treated self-poisoning. Aust N Z J Psychiatry. 2005;39(1-2):101-107.
38. Cooper J, Kapur N, Webb R, et al. Suicide after deliberate selfharm: a 4-year cohort study. Am J Psychiatry. 2005;162(2):297-303.

39. Owens D, Wood C, Greenwood DC, Hughes T, Dennis M. Mortality and suicide after non-fatal self-poisoning: 16-year outcome study. BrJ Psychiatry. 2005;187:470-475.

40. Chen VC, Tan HK, Chen CY, et al. Mortality and suicide after selfharm: community cohort study in Taiwan. Br J Psychiatry. 2011; 198(1):31-36.

41. Bergen $H$, Hawton $K$, Kapur N, et al. Shared characteristics of suicides and other unnatural deaths following non-fatal self-harm? A multicentre study of risk factors. Psychol Med. 2012;42(4):727-741.

42. Fazel S, Grann M, Ahlner J, Goodwin G. Suicides by violent means in individuals taking SSRIs and other antidepressants: a postmortem study in Sweden, 1992-2004. J Clin Psychopharmacol. 2007;27(5):503-506

43. Druss BG, Walker ER. Mental Disorders and Medical Comorbidity. Research Synthesis Report No. 21. Princeton, NJ: Robert Wood Johnson Foundation; 2011.

\section{CHANGE-OF-ADDRESS FORM FAMIIY MEDICDNE}

Please complete this form and mail to the following address or fax to Annals Circulation at 913-906-6080:

Annals of Family Medicine, Circulation Department, 11400 Tomahawk Creek Pkwy, Leawood, KS 66211-2680

Check if member of sponsoring organization:

$$
\begin{array}{ll}
\square \text { AAFP } & \square \text { ABFM } \square \text { STFM } \square \text { ADFM } \\
\square \text { AFMRD } & \square \text { NAPCRG } \square \text { CFPC }
\end{array}
$$

ID number from label on your journal cover

OLD Information (Please print.)

\begin{tabular}{ll}
\hline Name \\
\hline Company (if applicable) \\
\hline Address (Street plus Apt or Ste) \\
\hline City & \\
\hline Country & Postal Code (9-digit ZIP for US) \\
\hline Telephone & Fax \\
\hline E-Mail &
\end{tabular}

NEW Information (Please print.)

\begin{tabular}{lc}
\hline Name \\
\hline Company (if applicable) \\
\hline Address (Street plus Apt or Ste) \\
\hline City & \\
\hline Country & Postal Code (9-digit ZIP for US) \\
\hline Telephone & Fax \\
\hline E-Mail &
\end{tabular}

